\title{
RESEARCH
}

\section{A Structured Approach to Intentional Interprofessional Experiential Education at a Non-Academic Community Hospital}

\author{
Angela Shogbon Nwaesei, PharmD, ${ }^{\text {a }}$ Bobby C. Jacob, PharmD, ${ }^{\text {a }}$ Samuel K. Peasah, PhD, \\ Jonathan J. Perkins, MD, ${ }^{\text {b }}$ Matthew Hogan, MD $^{\mathrm{b}}$ \\ ${ }^{a}$ Mercer University College of Pharmacy, Atlanta, Georgia \\ ${ }^{\mathrm{b}}$ Emory Decatur Hospital, Decatur, Georgia
}

Submitted September 2, 2018; accepted February 4, 2019; published November 2019.

Objective. To develop and implement a multimodal structured approach to intentional interprofessional experiential education at a non-academic community hospital, and to evaluate students' perceptions of the program.

Methods. A multimodal structured approach to intentional interprofessional experiential education was designed that consisted of medical and pharmacy students participating together in daily prerounds, daily teaching rounds, and once or twice weekly lunch-and-learn sessions at a non-academic community hospital. Pre- and post-experience surveys were administered to assess students' perceptions of physician and pharmacist collaboration in interprofessional education (IPE). The survey instrument included the Student Perceptions of Physician-Pharmacist Interprofessional Clinical Education, Version 2 (SPICE-2) survey.

Results. Thirty-nine students, including 18 fourth-year student pharmacists from Mercer University College of Pharmacy and 21 third-year medical students from three medical schools in the Caribbean, provided informed consent and were enrolled in the eight-month study. Students' perceptions of items related to the Interprofessional Education Collaborative (IPEC) competencies, including values/ethics for interprofessional practice, roles/responsibilities, and teams and teamwork, significantly improved from the pre- to the post-experience survey.

Conclusion. A multimodal structured approach to intentional interprofessional experiential education had positive effects on students' perceptions of interprofessional clinical education targeting key components of the (IPEC) competencies. This approach may be a useful tool for implementing intentional IPE in the experiential setting.

Keywords: interprofessional education, intentional interprofessional experiential education, SPICE, advanced pharmacy practice experience, community hospital

\section{INTRODUCTION}

The Institute of Medicine's seminal publication on the importance of interprofessional education (IPE), a critical catalyst for reforming the modern healthcare system, stimulated widespread activity related to curricular restructuring in health science disciplines. ${ }^{1}$ Interprofessional education is defined by the World Health Organization as students from two or more professions learning about, from, and with each other to enable effective collaboration and improve health outcomes. ${ }^{2}$ Core competencies related to IPE and collaborative educational

Corresponding Author: Angela Shogbon Nwaesei, Mercer University College of Pharmacy, 3001 Mercer University Dr., Atlanta, GA.Tel: 678-547-6116.Email: Shogbon_ao@, mercer.edu. models have been developed and were most recently updated in 2016 by the Interprofessional Education Collaborative (IPEC). ${ }^{3}$ Accreditation standards across health science disciplines, including pharmacy and medicine, have clearly established the imperative of IPE in the core curriculum. ${ }^{4,5}$ The American Association of Colleges of Pharmacy (AACP) is recognizing the challenges of implementing IPE, specifically in the experiential setting, and has highlighted the need for educators to be deliberate in their efforts to implement intentional interprofessional experiential education in practice settings. ${ }^{6}$ Intentional interprofessional experiential education has been described as the "explicit effort by preceptors and practice sites to create/foster educational opportunities or activities designed to specifically achieve interprofessional education 


\section{American Journal of Pharmaceutical Education 2019; 83 (9) Article 7365.}

competencies." ${ }^{\circ}$ Specific challenges to the implementation of IPE in experiential settings include logistic conflicts related to scheduling, lack of administrative support, and inadequate infrastructure to support learning. ${ }^{6-9}$ These challenges are even more pronounced for pharmacy and medical educators in community hospital settings as there is often no centralized academic health center administrative support. The goal of recent initiatives related to intentional interprofessional experiential education is to foster environments where IPE can thrive and students are able to achieve IPE competencies in varied experiential settings, including inpatient practices. ${ }^{6}$

While many pedagogical studies have evaluated implementation of IPE in classroom settings, studies specifically examining intentional IPE in the experiential setting are limited. ${ }^{6}$ In addition, there are several limitations that characterize the studies that have been published from experiential settings, including that IPE experiences described have been predominantly confined to large academic medical centers. ${ }^{10-14}$ Furthermore, only a limited number of studies have been published evaluating IPE between student pharmacists and medical students in the inpatient setting. The majority of available studies of IPE in the experiential setting have also typically included a singular component to the IPE program, usually involving interprofessional interactions with patients, interprofessional team rounds, or review of patient case studies. ${ }^{13,15-17}$ Furthermore, these studies have not incorporated a multimodal approach to IPE involving multiple components in a single IPE program. ${ }^{13,15-17}$ Finally, in a survey by the AACP Task Force on Intentional Interprofessional Education in Experiential Education, the majority of IPE experiences reported in the experiential setting did not include an assessment of IPE competencies, which is a key component of intentional IPE in this setting. ${ }^{6}$

The objective of this study was to develop and implement a multimodal structured approach to intentional interprofessional experiential education at a non-academic community hospital, and to evaluate students' perceptions of interprofessional clinical education targeting IPEC competencies. We hypothesized that this multimodal structured approach to intentional interprofessional experiential education would have an effect on students' perceptions of interprofessional clinical education targeting key components of the IPEC competencies.

\section{METHODS}

This was a prospective study that involved the development, implementation, and evaluation of a multimodal structured approach to intentional interprofessional experiential education between student pharmacists and medical students in the inpatient setting. The study was conducted over an eight-month period during the 2017-2018 academic year. The study institution was a non-academic community hospital in a large metropolitan area of the United States. This institution served as a teaching site for student pharmacists from Mercer University College of Pharmacy, and offered a five-week advanced pharmacy practice experience (APPE) in medicine for fourth-professional year students. The medicine APPE students were precepted by two faculty members from the Mercer University College of Pharmacy, who served as investigators on this project. The hospital also served as a clinical education site for medical students from three separate medical schools based in the Caribbean. Third-year medical students from these institutions worked with several hospitalists on the internal medicine service during their sixweek medicine rotation. Student pharmacists completing their medicine APPE and medical students assigned to a specific hospitalist service run by two of the hospitalist physicians cared for patients from the same service. This provided an opportunity to develop a multimodal, structured approach to intentional interprofessional experiential education for these students. The components of this intentional IPE program included pre-rounds, teaching rounds, and lunch-and-learn sessions (Figure 1).

Pre-rounds involved daily, one-on-one interaction between student pharmacists and medical students to briefly discuss mutual patients from both medical and pharmacy perspectives, and to exchange recommendations related to patient care. Students were also encouraged to visit patients jointly when feasible so they could

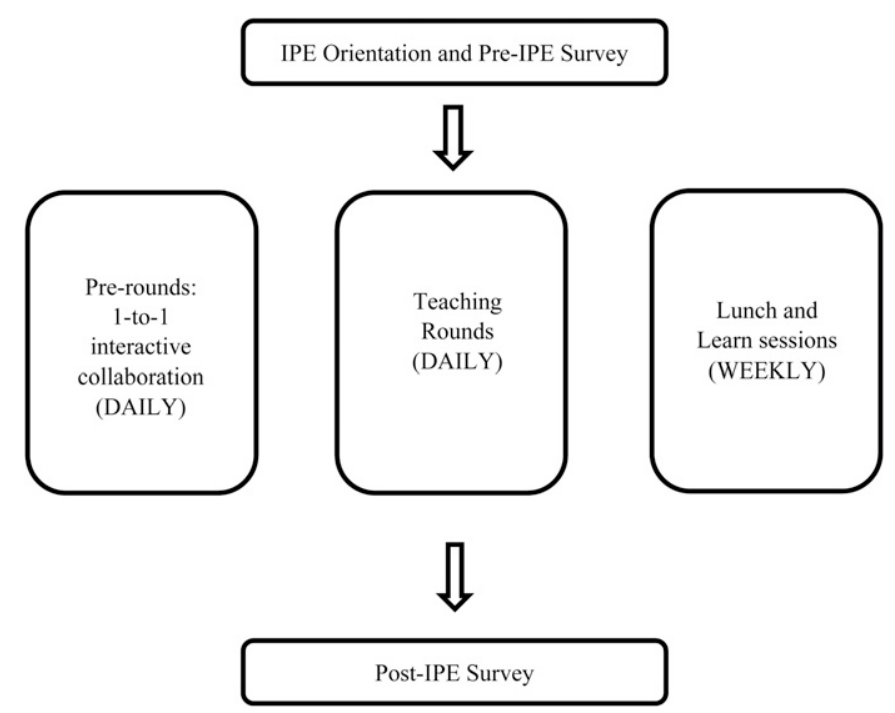

Figure 1. Multimodal Structured Approach to Intentional Interprofessional Experiential Education 


\section{American Journal of Pharmaceutical Education 2019; 83 (9) Article 7365.}

interview the patient together and learn from each other. Students completed pre-rounds without the assistance of the hospitalist physician or pharmacy faculty member.

Teaching rounds, which were already being offered at this study institution, were continued as a component of the intentional interprofessional experiential education program. Teaching rounds involved daily interdisciplinary interaction between the attending hospitalist physician, the pharmacy faculty preceptors, medical resident, pharmacy residents, student pharmacists, and medical students. These teaching rounds provided opportunities for patient presentation and discussion with the team members, in addition to discussion led by the hospitalist and pharmacy faculty members regarding relevant clinical topics.

The third and final component of this program involved lunch-and-learn sessions, which were offered once or twice weekly. The focus of these sessions was to review and discuss evidence-based guidelines related to providing patient care for several diseases commonly encountered in internal medicine. All students were provided with the guideline reference and learning objectives ahead of each specific session, and students were expected to review these documents prior to the session and come prepared to lead a group discussion with the other students. Students were expected to lead this discussion independently. Pharmacy faculty members observed the discussion from an adjacent room and were available at the end of the discussion to address questions from the group and to clarify areas of uncertainty. The attending hospitalist physicians were not present during these sessions, but were available to discuss any additional areas of uncertainty with the interprofessional team during teaching rounds.

Several scales have been published to measure student perceptions and learning with IPE. ${ }^{18}$ The Student Perceptions of Physician-Pharmacist Interprofessional Clinical Education, Version 2 (SPICE 2) survey was used in this study. The SPICE 2 is a validated survey instrument designed to evaluate student perceptions of collaborative practice between physicians and pharmacists. It focuses on the potential impact of collaborative practice on students' values, patient care, and educational preparedness (Appendix 1). ${ }^{18,19}$ The survey instrument consists of 10 items that align with the IPEC Core Domains of Values/Ethics for Interprofessional Practice, Roles/Responsibilities, and Teams and Teamwork. ${ }^{18}$ The instrument uses a five-point Likert scale ranging from strongly disagree $=1$ to strongly agree $=5$.

To evaluate this educational intervention, a pre- and post-experience survey was developed by the faculty investigators and administered as part of this study. The pre-experience survey included questions on baseline demographics and an assessment of students' perceptions of interprofessional clinical education using the SPICE 2 instrument. The survey was administered on the first day of the clinical rotation after students completed an orientation to the program. The post-experience survey assessed students' perceptions of interprofessional clinical education (using the SPICE 2 instrument) and the effectiveness of the educational intervention, and included a free text field for students to provide any additional feedback about the learning experience. To assess the effectiveness of the educational intervention, students were asked to rate the effectiveness of each IPE learning activity on a scale ranging from not effective to very effective. Students were asked to complete the post-experience survey on the last day of their rotation. These surveys were administered electronically using the Qualtrics data collection software (Qualtrics Labs, Provo, UT). While both student pharmacists and medical students were required to participate in the IPE program as part of their clinical responsibilities at the site, participation in the pre-IPE and post-IPE surveys was voluntary, and informed consent from each participant was obtained prior to enrollment. The Institutional Review Board of the Mercer University College of Pharmacy approved this study prior to its implementation.

Descriptive statistics of demographic data and analysis of the outcomes of the study were conducted using SAS software, version 9.3 (SAS Institute, Cary, NC). The students' responses pre- and post-experience to the Likertscale items on the SPICE 2 survey were analyzed for changes in students' perceptions by comparing the proportion of students who agreed or strongly agreed on the pre vs post survey for each of the questions using chisquare statistics. Statistical significance was set a priori as $p<.05$. The qualitative responses to the open-ended questions were analyzed and summarized as emerging themes using NVivo, version 9 software (QSR International, Burlington, MA).

\section{RESULTS}

During the study period, 39 students completed a medicine rotation at the study institution as either a student pharmacist or medical student. All 39 students provided informed consent for participation in the study and completed the pre-experience survey. Thirty-six students, including 18 student pharmacists and 18 medical students, completed the post-experience survey (Table 1). All student pharmacists (100\%) reported having prior IPE experience as compared with $20 \%$ of medical students.

More than $75 \%$ of students had positive baseline perceptions (agreed or strongly agreed) about the majority 


\section{American Journal of Pharmaceutical Education 2019; 83 (9) Article 7365.}

Table 1. Demographics of Participants in a Study Assessing a Multimodal Structured Approach to Intentional Interprofessional Experiential Education $(\mathrm{n}=39)$

\begin{tabular}{lc}
\hline Variable & No. $(\mathbf{\%})$ \\
\hline Discipline & \\
Pharmacy & $18(46)$ \\
Medicine & $21(54)$ \\
Gender & \\
Male & $14(36)$ \\
Female & $25(64)$ \\
Age, years & \\
18-24 & $5(13)$ \\
$25-29$ & $25(64)$ \\
$30-34$ & $3(8)$ \\
$35-44$ & $4(10)$ \\
45 and above & $2(5)$ \\
Past IPE Experience & \\
Yes & $22(58)$ \\
No & $16(42)$ \\
\hline
\end{tabular}

of items on the SPICE 2 pre-experience survey. Despite this, students showed significant improvement $(p<.05)$ in their perceptions in the post-experience survey on items related to the three areas of the IPEC competencies assessed, including values/ethics for interprofessional practice, roles/responsibilities, and teams and teamwork (Table 2). In addition, the majority of students found all three components of this structured IPE program to be effective or very effective, including $86 \%$ of students for the pre-rounds, $97 \%$ for the teaching rounds, and $88 \%$ of students for the lunch-and-learn sessions.

In the free-text field provided for students' qualitative feedback, students provided positive comments on the IPE experience three times more often than negative comments. The prominent themes in the comments were sorted into six categories, including activities, insight, interdisciplinary, patient care, negatives, and positives. The most common themes were positive, with students using words like "active learning," "gratitude," "value," and "good learning experiences." Student pharmacists commented that the experience provided "an excellent opportunity to see the roles of other healthcare professionals on the team and to interact with them in a way that truly showed the roles of both pharmacists and physicians for patient care." Another mentioned that the experience helped to "break the ice" between the professions and that every APPE should offer similar activities. Medical students also said that they enjoyed and appreciated the experience. One stated that he had learned a great deal from the pharmacy students about "how to approach medication therapy" and that the faculty members had "crystallized the salient guideline points for us at each session." The students noted areas for improvement as well.
Some of the constructive criticisms included limiting the lunch-and-learn sessions to once a week and limiting the number of key points discussed at these events to avoid rushing through the material.

\section{DISCUSSION}

In this paper we describe a unique, multimodal, structured approach to intentional interprofessional experiential education at a non-academic community hospital between student pharmacists from a college of pharmacy and medical students from three Caribbean universities. To our knowledge, this is the first such publication of its kind. This experience fulfilled accreditation standards for both pharmacy and medical education, and for the majority of medical students, this was their first exposure to IPE in their curriculum. This study found significant improvement in students' perceptions of physician-to-pharmacist interprofessional collaboration and clinical education when IPEC competency areas were assessed. These differences were found despite the majority of students having prior IPE exposure. In addition, the majority of students found all three components of the structured IPE program to be effective or very effective, and they provided positive qualitative feedback. These findings are in line with our research hypothesis that a multimodal, structured approach to intentional, interprofessional experiential education would have an effect on students' perceptions of interprofessional clinical education targeting key components of the IPEC competencies.

On the pre-experience survey, the majority of students had positive baseline perceptions about pharmacistphysician clinical education. Higher baseline perceptions of IPE have also been observed in other studies. ${ }^{14,16,20}$ Despite higher baseline perceptions, a significant increase was observed in the number of students who agreed or strongly agreed with several items on the post-experience survey. In the post-experience survey, more students appeared to better perceive the value of working with other health professions students on enhancing their education and future ability to work on an interdisciplinary team. This finding is similar to what was reported by Rotz and colleagues after implementation of an interprofessional experiential six-semester course series, and in the follow-up study comparing students perceptions after one and two years of exposure to this program. ${ }^{21,22}$ These positive changes on the SPICE survey were also observed by Theodorou and colleagues in a study evaluating an IPE experience between dental and pharmacy students at a dental clinic. ${ }^{16}$ In addition, in this study, more student pharmacists and medical students appeared to gain an understanding of each other's training requirements and perceived the value of an 


\section{American Journal of Pharmaceutical Education 2019; 83 (9) Article 7365.}

Table 2. Student Perceptions of Physician-Pharmacist Interprofessional Clinical Education, Version 2 (SPICE 2) Responses $(\mathrm{n}=36)$

\begin{tabular}{|c|c|c|}
\hline & Pre-Survey (\%) & Post-Survey (\%) \\
\hline $\begin{array}{l}\text { 1. Working with another discipline of students } \\
\text { enhances my education }\end{array}$ & 89 & $97^{\mathrm{a}}$ \\
\hline $\begin{array}{l}\text { 2. My role within the interdisciplinary team is } \\
\text { clearly defined }\end{array}$ & 78 & 97 \\
\hline $\begin{array}{l}\text { 3. Patient satisfaction is improved when patients } \\
\text { are treated by a team of professionals from } \\
\text { different disciplines }\end{array}$ & 100 & 86 \\
\hline $\begin{array}{l}\text { 4. Participating in educational experiences with } \\
\text { another discipline of students enhances my } \\
\text { future ability to work on an interdisciplinary } \\
\text { team }\end{array}$ & 89 & $97^{\mathrm{a}}$ \\
\hline $\begin{array}{l}\text { 5. I have an understanding of the courses taken } \\
\text { by, and training requirements of, both } \\
\text { pharmacy and medical students }\end{array}$ & 56 & $83^{\mathrm{a}}$ \\
\hline $\begin{array}{l}\text { 6. Health care costs are reduced when patients } \\
\text { are treated by a team of professionals from } \\
\text { different disciplines }\end{array}$ & 78 & $89^{a}$ \\
\hline $\begin{array}{l}\text { 7. All health professions students should be } \\
\text { educated to establish collaborative } \\
\text { relationships with members from other } \\
\text { disciplines }\end{array}$ & 97 & 97 \\
\hline $\begin{array}{l}\text { 8. I understand the roles of other professionals } \\
\text { within the interdisciplinary team }\end{array}$ & 81 & 94 \\
\hline $\begin{array}{l}\text { 9. Patient-centeredness increases when care is } \\
\text { delivered by a team of professionals from } \\
\text { different disciplines }\end{array}$ & 97 & 97 \\
\hline $\begin{array}{l}\text { 10. During their education, medical and } \\
\text { pharmacy students should be involved in } \\
\text { teamwork in order to understand their } \\
\text { respective roles }\end{array}$ & 100 & 94 \\
\hline
\end{tabular}

Table represents comparison of the collapsed Likert scale comparing proportion of students who agreed/strongly agreed on the pre- vs. postsurvey

${ }^{\mathrm{a}} p<.05$ for the difference between the pre- and post-survey responses

interprofessional team in helping to reduce health care costs. This is similar to students' perceptions on the SPICE survey in prior studies by MacDonnell and colleagues and Theodorou and colleagues, and displays students' perceptions of the value of interprofessional teamwork on health outcomes. ${ }^{16,23}$ These findings are also of note as this survey assesses key IPEC competencies that students are expected to develop and display as they prepare for professional practice. In addition, collaboration as a member of an interprofessional team is one of the core entrustable professional activities for both student pharmacist and medical student education. ${ }^{24,25}$

Our study involved an intentional approach to interprofessional experiential education in the inpatient setting. A commentary by Grice and colleagues, based on the report of the AACP Task Force on Intentional
Interprofessional Education in Experiential Education, discussed the importance and need for intentional IPE in the experiential setting and highlighted the lack of studies incorporating this approach to IPE in this setting. ${ }^{6}$ Intentional interprofessional experiential education involves deliberate efforts by preceptors and practice sites to foster environments where IPE can thrive and students are able to achieve IPE competencies. ${ }^{6}$ This study was designed to develop and implement an intentional IPE program aimed at developing students in the IPEC core competencies of values/ethics, roles/responsibilities, interprofessional communication, and teams and teamwork. Specifically, each of the three components of this IPE program (pre-rounds, teaching rounds, and lunchand-learn sessions) provided the opportunity for students to practice interprofessional communication in a variety 


\section{American Journal of Pharmaceutical Education 2019; 83 (9) Article 7365.}

of areas, including during one-on-one patient case collaborative discussions, on teaching rounds, and during discussions on the guideline-based topics assigned for lunch-and-learn sessions. The program also provided opportunities for students to learn about each other's training and roles on the team and to engage in peer teaching. Furthermore, students had the opportunity to develop team dynamics, engage in regular teamwork, and build values/ethics as they worked together to identify and solve patient care issues to ensure the best health outcomes for their patients.

Previous studies on IPE between student pharmacists and medical students in the experiential setting have mainly described a singular component to the IPE program, which typically involved interdisciplinary rounds, an interprofessional patient case activity, or a patient assessment and formulation of care plans, but did not typically incorporate both the patient care management component and interprofessional topic discussions led by students. ${ }^{13,15-17}$ This study incorporated a multimodal, structured approach to intentional interprofessional experiential education that consisted of three distinct components in a single IPE program. This provided several opportunities for students to interact with and learn from each other through different avenues, including during the patient care management components involved in the prerounds and teaching rounds, as well as through discussion of evidence-based guidelines during the lunch and learn sessions. This study highlights the feasibility of a multimodal approach to IPE in a single IPE program in the experiential setting and provides a perspective on the opportunity for students to learn as an interprofessional team through different modes in a single program.

In addition, the majority of studies on IPE between student pharmacists and medical students have been limited to large academic medical centers such as Thomas Jefferson University, Mayo Clinic, Columbia University Medical Center, and University of Kansas Medical Center, among others. ${ }^{10-14}$ However, relatively large numbers of student pharmacists and medical students receive experiential clinical instruction at community hospitals. Non-academic, community-based hospitals can pose a potential challenge as there is often no academic health science infrastructure to rely on and hospital administrators in these settings have no professional connections to the academic institutions from which students come, but instead work with affiliation agreements. Furthermore, not every community hospital serves as a teaching site for students from multiple health professions. In the case of our study, the investigators developed relationships across disciplines at administrative levels, which aided with facilitating opportunities for the development and implementation of structured and intentional opportunities for interprofessional learning and education between health professions students. This structured approach overcame logistic challenges to the implementation of IPE by creating a structure that proved feasible and sustainable. This study provides a model for implementation of intentional interprofessional experiential education in non-academic community-based hospital settings, and highlights that community hospitals can be viable sites for student instruction and interprofessional learning.

This study had a few limitations. The study investigators developed open-ended questions for knowledge assessment of topics covered in the discussion of the evidence-based guidelines. Thus, the length and complexity of the students' responses differed, making consistent evaluation of the data difficult. Therefore, this data was not included in our study results. A multiple-choice knowledge assessment may have afforded a more convenient and consistent approach to student assessment. Based on the nature of the medicine rotation, this study only included student pharmacists and medical students on one hospitalist's team at one institution. Also, this study only included students completing experiential education during a single academic year; thus, there were a limited number of participants. The small number of participants limited our ability to conduct subgroup analyses, such as examining differences in perception between pharmacy and medical students, as well as the impact of gender and prior IPE experience on students' perceptions. Future plans include implementation of the program for all student pharmacists and medical students at the institution; eventual expansion to other health professions students, including nursing students, and continued data collection and analysis over several years. While the investigators anecdotally observed greater interactions between student pharmacists and medical students, objective evaluation of behavior changes would be a useful tool to show the value of interprofessional clinical education and attainment of IPEC competencies. Assessment of patient care interventions made and acceptance rates following implementation of interprofessional clinical education would also aid with determining the impact of the program on patient outcomes.

\section{CONCLUSION}

A multimodal structured approach to intentional interprofessional experiential education was successfully developed and implemented in a non-academic community hospital. Positive effects on students' perceptions of interprofessional clinical education targeting key components of the IPEC competencies were observed. These findings highlight the potential of using this approach to IPE as a tool for successful implementation of intentional IPE at non-academic community hospitals. 


\section{American Journal of Pharmaceutical Education 2019; 83 (9) Article 7365.}

\section{ACKNOWLEDGMENTS}

The authors would like to acknowledge Gina Ryan, PharmD, for her contributions toward the review and revision of this manuscript.

\section{REFERENCES}

1. Greiner AC, Knebel E. Committee on the Health Professions Education Summit. Health Professions Education: A Bridge to Quality. Washington, DC National Academy Press; 2003. http:// www.nap.edu/catalog/10681.html. Accessed June 15, 2018.

2. World Health Organization. Framework for action on interprofessional practice \& collaborative practice. http:// www.who.int/hrh/resources/framework_action/en/. Accessed July 23, 2018.

3. Interprofessional Education Collaborative. 2016. Core competencies for interprofessional collaborative practice: 2016 update. Washington, DC: Interprofessional Education Collaborative. https://www.ipecollaborative.org/resources.html. Accessed June 15, 2018.

4. LCME Functions and Structure of a Medical School. Standards for accreditation of medical education programs lading to the MD degree. http://lcme.org/publications/. Accessed July 23, 2018. 5. Accreditation Council for Pharmacy Education (ACPE). Accreditation standards and key elements for the professional program in pharmacy leading to the doctor of pharmacy degree. Standards 2016. https://www.acpe-accredit.org/pharmd-programaccreditation/. Accessed July 20, 2018.

6. Grice GR, Thomason AR, Meny LM, Pinelli NR, Martello JL, Zorek JA. Intentional interprofessional experiential education. Am J Pharm Educ. 2018;82(3):Article 6502.

7. Jones KM, Blumenthal DK, Burke JM, et al. Interprofessional education in introductory pharmacy practice experiences at US colleges and schools of pharmacy. Am J Pharm Educ.

2012;76(5):Article 80.

8. Buring SM, Bhushan A, Broeseker A, et al. Interprofessional education: definitions, student competencies, and guidelines for implementation. Am J Pharm Educ. 2009;73(4):Article 59 9. Alexandraki I, Hernandez CA, Torre DM, Chretien KC. Interprofessional education in the internal medicine clerkship postLCME standard issuance: results of a national survey. J Gen Intern Med. 2017;32(8):871-876.

10. Poirier TI, Newman K. Advancing interprofessional education via strategic planning. Am J Pharm Educ. 2016;80(4):Article 56. 11. Lyons KJ, Giordano C, Speakman E, Anthony R. Jefferson interprofessional clinical rounding project: an innovative approach to patient care. J Allied Health. 2013;42(4):197-201.

12. Maldonado AQ, Bray BS, Woodard LJ, et al. Impact of participation on a solid organ transplant team on student pharmacists' perceptions of interprofessional roles. Am J Pharm Educ. 2013;77 (4): Article 74.

13. Patel K, Desai U, Paladine H. Development and implementation of an interprofessional pharmacotherapy learning experience during an advanced pharmacy practice rotation in primary care. Curr Pharm Teach Learn. In press April 26, 2018. https://doi.org/10.1016/ j.cpt1.2018.04.014. Accessed May 15, 2018.

14. Zaudke JK, Paolo A, Kleoppel J, Phillips C, Shrader S. The impact of an interprofessional practice experience on readiness for interprofessional learning. Fam Med. 2016;48(5):371-376. 15. Anderson E, Lakhani N. Interprofessional learning on polypharmacy. Clin Teach. 2016;13(4):291-297.

16. Theodorou J, Rotz M, Macphail L, et al. Designing and evaluating an interprofessional practice experience involving dental and pharmacy students. Am J Pharm Educ. 2018; 82(6):Article 6298. 17. Zorek JA, MacLaughlin EJ, Fike DS, MacLaughlin AA, Samiuddin M, Young RB. Measuring changes in perception using the Student Perceptions of Physician-Pharmacist Interprofessional Clinical Education (SPICE) instrument. BMC Med Educ. May 2014;14:101.

18. Shrader S, Farland MZ, Danielson J, Sicat B, Umland EM. A systematic review of assessment tools measuring interprofessional education outcomes relevant to pharmacy education. Am J Pharm Educ. 2017;81(6):Article 119.

19. Zorek JA, Fike DS, Eickhoff JC, et al. Refinement and validation of the student perceptions of physician-pharmacist interprofessional clinical education instrument. Am J Pharm Educ. 2016;80(3):Article 47. 20. Shrader S, Griggs C. Multiple Interprofessional education activities delivered longitudinally within a required clinical assessment course. Am J Pharm Educ. 2014;78(1):Article 14. 21. Rotz ME, Dueñas GG, Zanoni A, Grover AB. Designing and evaluating an interprofessional experiential course series involving medical and pharmacy students. Am J Pharm Educ.

2016;80(5):Article 85.

22. Rotz ME, Grover AB, Burden A, Pontiggia L, Duenas GG. A cross-sectional study evaluating the impact of one year versus two years of exposure to interprofessional education on student perceptions of physician-pharmacist interprofessional clinical education (SPICE). Innov Pharm. 2016;7(3):Article 13.

23. MacDonnell C, George P, Nimmagadda J, Brown S, Gremel K. A team-based practicum bringing together students across educational institutions and health professions. Am J Pharm Educ. 2016;80(3):Article 49.

24. Haines ST, Pittenger AL, Stolte SK, et al. Core entrustable professional activities for new pharmacy graduates. Am J Pharm Educ. 2017;81(1):Article S2.

25. Association of American Medical Colleges. The core entrustable professional activities (EPAs) for entering residency. https:// www.aamc.org/initiatives/coreepas/. Accessed July 24, 2018. 


\section{American Journal of Pharmaceutical Education 2019; 83 (9) Article 7365.}

Appendix 1. Student Perceptions of Physician-Pharmacist Interprofessional Clinical Education (SPICE) 2 Instrument ${ }^{19}$ The purpose of this instrument is to assess perceptions of medical and pharmacy students in interprofessional clinical education. Please be completely honest as you rate the extent of your agreement with each of the following statements.

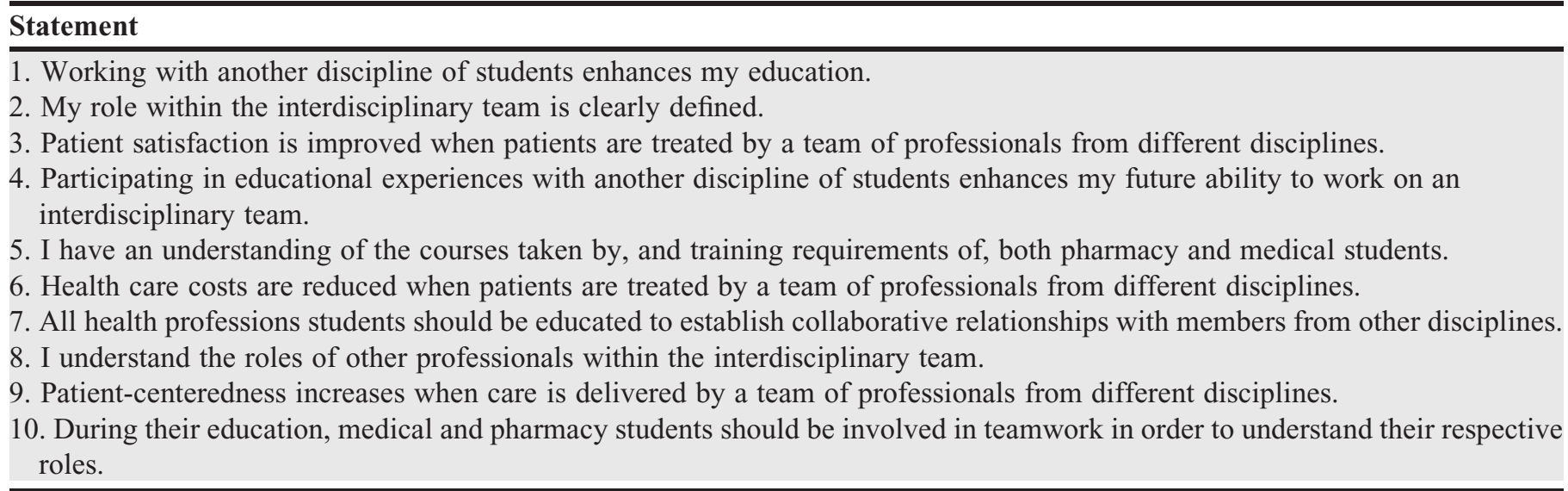

$1=$ strongly disagree, $2=$ disagree, $3=$ neutral, $4=$ agree, $5=$ strongly agree

Appendix 2. Additional Student Survey Comments Regarding the Interprofessional Education Experience

\section{Pharmacy Students}

This experience provided an excellent opportunity to see the roles of other healthcare professionals on the team and to interact with them in a way that truly showed the roles of both pharmacists and physicians for patient care.

It was a great experience to work together with other students and see how they work up patient.

I really enjoyed being able to learn with the med students.

It was enjoyable to work with medical students and assess their drug knowledge from what they learned in school.

it was a great experience I had with the IPE. It makes my assessment and plan for the patient easier because I get to update on some of medical assessments medical students are capable of doing. It helps to see what role each profession have and how we can optimize our patient care together. It helps break the ice between the two professions and help us see we need each other for better outcome of the care we are providing, I believe every rotation should adopt such kind of activity in APPE.

The pre-round sessions were very helpful to see what information the medical student could get from the patient. They may have asked some of the same questions that I had. Seeing their perspective on the diagnosis and why was also helpful because we may not get that information until rounds.

Overall, it was an informative experience. Hearing how other clinicians practice and learning their perspective is beneficial to patient care. It assists one in treating a patient when they can incorporate the viewpoint of their counterpart.

It was interesting learning about what medical students do. The table rounds were interesting and informative.

The IPE experiences at DeKalb Medical center were very helpful in learning and understanding the topic. This will definitely help the students from both area pharmacy and medicine. Please continue to do this type of IPE activities.

\section{Medical Students}

I loved having rounds with the pharmacy students, where we would all sit and discuss our patients with the doctor. I also really liked preparing/having the lunch and learns. Preparing for the lunch and learns was a fair bit of work, the articles were long and to be honest I mostly looked at my text books and then went to the articles for details that my books did not contain. I didn't read the articles start to finish. I felt that $i$ had a much greater understanding of each of the topics covered after having the lunch and learn visits with the pharm students. I also enjoyed the lunch vouchers, it was a special treat in the week but I would have done the lunch and learns even without them.

I found that some of the pharmacy students were stressed when we would round on the patients together. I would want to see a patient before they were ready. I prefer to look at the chart briefly for labs and vitals then get most of my information right from the patient if possible, which means I'm ready earlier to see the patient. I felt like I was wasting my time waiting for the pharm students to be ready to see the patient, not a serious problem and I know it's important for us to work together but that provided me some stress as a result because I do most of my work after seeing the patient not before.

I really enjoyed having discussions with Bobby and Angela, I felt like I learned a great deal from them and was thankful to have some more professionals to ask questions of besides just my physician preceptors. Overall I really enjoyed this experience and while it was extra work I feel like it was definitely worth it and my comprehension of the topics reviewed improved immensely. 


\section{American Journal of Pharmaceutical Education 2019; 83 (9) Article 7365.}

I enjoyed the experience of working with the pharmacy students/ Angela and Bobby- they were invaluable when it came to learning about treatments and just having someone to discuss an assessment and plan with! (Thank you guys!). Please try to limit a lunch and learn to once a week. having 2 lunch and learns and a grand rounds in 1 week can be a bit overwhelming. Please use the same guideline questions in the initial document emailed to us for the lunch and learn-giving us a second guideline to follow right before the lunch learn makes me feel unprepared. If possible, try to keep lunch and learn questions to 7 key points you want us to focus on as sometimes we were rushing through material. Everyone should participate- everyone should be able to answer every question but maybe assigning questions (right before the lunch and learn) to each person would be better that way everyone speaks. Summary sheets should be provided at the end of each lunch- learning only occurs when you revisit concepts (having something quick to refer to would be nice!)- Perhaps this task can be provided to a new student each week

It was a good experience, thank you!

The lunch and learn sessions made me review high yield and pertinent medical information, and I am a better person because of it. Enjoyed the sessions. They were time consuming for me because of shelf exam preparations. The pre rounding was useless to me. Lunch and learn was nice. Once a week is better than twice a week. Overall it was nice interacting with pharm students. This helps me be more comfortable with interdisciplinary teams. THANKS MERCER!

Good experience. Learned about what pharmacy students' scope of learning is as a med student, we learn dosing and frequency later on (after Step 3). Our primary concern is diagnosis, next steps, and appropriate treatment.

It was helpful to learn about other disciplinaries in medicine. I enjoyed combining the knowledge of medical students and pharmacy students to tackle a subject. It was beneficial to understand the responsibilities of both pharmacists and clinicians.

I would like to thank the pharmacy professors, Dr. Shogbon and Dr. Jacobs for facilitating the excellent learning discussions after each session. We all enjoyed engaging and learning with the two teams of pharmacy students throughout our six-week rotation at DeKalb. I have learned a great deal from the students in how to approach medication therapy and the professors crystallized the salient guideline points for us at each session. Thank you for this rich and enjoyable learning experience.

I truly enjoyed this experience, I feel like I learned a lot form the pharmacy students and from Dr. Bobby. I highly recommend the continuation of the program for future students. Thank you for allowing me to be part of it.

It was a great experience and fantastic approach to be able to share ideas with other students in medical field especially pharm students.

It was a great experience. I wouldn't change anything!

No negative comments. It is a good interactive way to enhance the medical students' knowledge and application of medication on Pts treatment. Preceptors are great too. 